\title{
Knee injury patterns among young basketball players in Cape Town
}

\author{
Quinette Louw (MASP)' \\ Karen Grimmer (PhD) ${ }^{2}$ \\ Kit Vaughan $(\mathrm{PhD})^{3}$
}

'Department of Physiotherapy, University of the Western Cape, Bellville/University of South Australia, Adelaide

${ }^{2}$ Centre of Allied Health Research, University of South Australia, Adelaide

${ }^{3}$ Department of Human Biology, University of Cape Town

\begin{abstract}
Objective. The objective of this study was to ascertain the current knee injury prevalence among young basketball players in Cape Town.

Design. A retrospective survey was conducted in 2000 to capture information on injuries sustained during the season.

Setting. 458 young competitive basketball players in Cape Town, including 122 club players and 336 school basketball players, participated in the study.

Results. General injury rate was reported in $40.6 \%$ of players. The knee joint was the most common injury, representing $32 \%(N=304)$ of all injuries reported. The probability of sustaining a knee injury was significantly higher than sustaining any other injury (OR 1.31,95\% Cl $1.15-1.50)$, School players were less likely to sustain a knee injury than the club players (OR $0.62,95 \% \mathrm{Cl} 0.42$ $-0.93)$. Most of the knee injuries $(48.6 \%)$ were sustained during competitions. No significant difference in knee injury was found between boys and girls (OR 1.19, $\mathrm{Cl}$ $0.73-1.95$ ). The most common overall injury mechanism among both boys and girls was landing badly from a jump $(37,5 \%, N=144)$. Injuries resulting in loss of five or more player opportunities, L.e. practice or competition, were regarded as more serious injuries and represented $14.4 \%$ of all knee injuries.
\end{abstract}

Conclusions. The knee injury rate among young bas-

\section{CORRESPONDENCE:}

\section{Quinette Louw}

Department of Physiotherapy

University of the Western Cape

PO Box X17

Bellville

7500

Tel: 021-959 2542

Fax: 021-930 8370

Email: qlouw@uwc.ac.za ketball players in Cape Town is high. Better awareness of the epidemiology might improve coaches parents and health professionals understanding and manage ment of knee injuries among young basketball players.

\section{Introduction}

Basketball is currently the fastest growing sport in South Africa, with a growth rate of approximately $16 \%$ per year since $1986^{5}$ (and J Grobler, BMI Sports Info, Rivonia unpublished data). The prevalence of injuries is often consistent with the trends in sports participation and an increasing number of young South Africans are therefore at risk of sustaining an injury while playing basketball. ${ }^{12}$

Ankle and knee injuries are by far the most common injury types sustained during basketball.9.13 However, since the knee is the most complex and incongruent joint in the body, injuries are usually more serious and frequently surgery or hospitalisation is required..$^{13,17}$ Cost of injury is a way of measuring the severity and impact of injury. In Australia it has been determined that although knee injuries account for $12 \%$ of total sports injuries, they represent $25 \%$ of the total injury cost. ${ }^{17}$ Similarly, knee injuries among American high school boys also account for $12 \%$ of all injuries but $32 \%$ of all medical cost. ${ }^{16}$ In a total population of a Swedish municipality, the most severe injuries while playing sport involved the knee and resulted in the highest mean injury cost (US \$553). ${ }^{3}$

Basketball is a dynamic sport characterised by repetitive jumping, running, sharp changes in direction and sideways cutting manoeuvres. The loads and kinetic forces placed on the body during basketball may be related to the high prevalence of injuries, particularly to the lower limb. Knee injury rate in basketball varies between $20 \%$ and $28 \%$, and is higher than injury to other body parts. ${ }^{6,8,9,17}$ Previous research found that basketball had the highest frequency as well as severity of knee injuries. ${ }^{6,9,20}$ Health-related benefits gained from participating in physical activity are well recognised. Although it is advantageous that 23500 South African school children now have access to basketball, the negative side-effects such as lower limb injury should not be underestimated. ${ }^{5}$ 
Common knee injury types sustained during basketball include traumatic ligamentous lesions and overuse injuries such as patellar tendinitis and tendinosis. ${ }^{8,13}$ The anterior cruciate ligament is the most frequently injured of all the knee ligaments and can constitute a severe and long-lasting problem. ${ }^{17}$ Non-contact mechanisms such as landing from a jump have been identified as the most common mechanism of anterior cruciate ligament injuries. ${ }^{17}$ Basketball thus presents a high risk for serious injuries to the knee due to the repetitive jumping and landing nature of the sport.

Despite the popularity of basketball there is a lack of information on the epidemiology of injuries. This lack of research may reflect the traditional view that basketball is a non-contact sport and is therefore expected to be safer compared with contact sports such as rugby. A Medline, Cinahl and Current Contents and Sports Discus search since 1990 revealed only 7 studies reporting on basketball injuries. ${ }^{1,6,8,11,12,15,19}$ These studies include 4 prospective American surveys, 1 Danish survey, 1 Australian clinic-based survey and a prospective study. Four of these studies reported on basketball injuries in particular and the others reported on high school sports in general. The basketball studies investigated the apparently higher knee injury rate among girls compared with boys. Information regarding other associated injury factors such as injury mechanisms was generally lacking. Furthermore the studies based on clinic records were unable to determine the injury risk since the size of the population at risk was not reported. Comparison of injury rate between studies is constrained by methodological differences, variations in calculating or estimating exposure time, etc. Injury in all these studies was defined as one that occurred in an organised practice or game, resulting in loss of time from practice or competition or necessitating medical consultation. These studies did not report on less severe injuries where players may have continued playing. Knee injury rates of $10-20 \%$ were reported in all the studies, but these may be low, because of the restricted sampling and injury definition. ${ }^{1,6,8,12,15,19}$

No African studies reporting basketball injury rates were found from a manual search of sports journals in addition to searching the databases mentioned above. In South Africa there has been a dramatic increase in number of players from previously disadvantaged communities since 1994 and the true rate of knee injury may be different than that reported, but there are no African studies available. ${ }^{5}$ An inadequate number of coaches to teach good fundamental techniques, inappropriate facilities, poor playing surfaces and inadequate management of injuries due to poorer socio-economic circumstances may influence the injury patterns of young basketball players in South Africa. The aim of this study was to report on the knee injury prevalence, nature and mechanism among young basketball players in Cape Town.

\section{Methodology}

\section{Ethical approval}

The Western Cape Basketball Association and The United School Sports Association of South Africa (USSASA) granted permission in writing to conduct the study. Ethical approval to conduct the study was obtained from the University of the Western Cape. A letter outlining the project aims and participation of the players was sent to all parents. Players who participated provided a signed consent form from their parents to their coach or the principal researcher.

\section{Study design measurement tool}

A retrospective questionnaire survey was conducted to capture information on injuries sustained during one season. An injury was defined as one that occurred during practice or competition resulting from a traumatic incident. In addition the definition also encompassed overuse type of injuries not initiated by a specific traumatic event but causing symptoms such as pain and swelling while or after playing basketball. Thus the prerequisite that injury must result in loss of play did not apply to this study and loss of play merely served as an indication of severity. The questionnaire design was adapted from a validated questionnaire used in the 'Survey of participation and injury sustained during recreational activity in South Australia'. ${ }^{9}$ The questionnaire was adapted to collect data retrospectively over one season from South African basketball players and to provide detailed information regarding knee injuries (Table I). Players could nominate all body parts injured during the past season, and then reported details regarding a maximum of 3 knee injuries they sustained last during the season.

\section{Data collection}

Letters briefly outlining the project aims, particularly information regarding data collection, were sent to the contact person for all registered clubs and schools with young players. Suitable times and venues for data collection were then confirmed.

\section{Data collection method}

Data were collected during the last 3 weeks of the season to optimise recording of all injuries that occurred during the entire season. Clubs played during the winter season (April October 2000) and schools played during the summer (November 2000 - March 2001) since most schools only

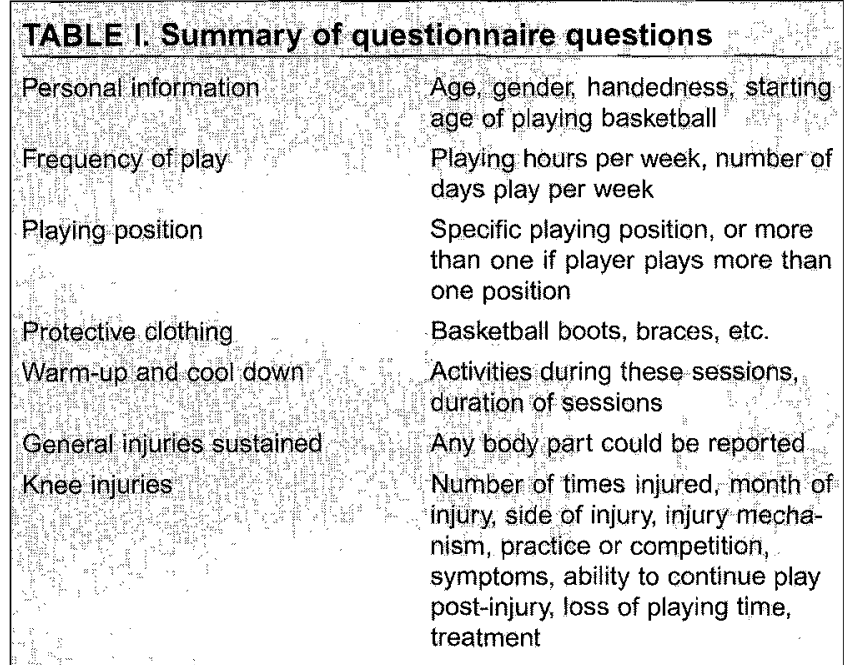


have outside courts. To be eligible to participate all players had to be registered to play in competition.

\section{Data collection for clubs}

Eleven of the 12 clubs in the Western Cape Basketball Association with young players participated in the survey. The 12th club was not contactable. Data were collected in person at training sessions and competitions by the principal researcher and an assistant. Coaches administered the questionnaire to players who were absent from training or competition on the day of data collection.

\section{Data collection for schools}

Eighteen of the 28 high schools registered for the basketball season with the United School Sports Association participated in the survey. Contact persons at the 10 remaining schools were either not contactable (6 schools), the school withdrew its team from competitions ( 2 schools) or a suitable data collection time was not possible within the school programme (2 schools). Data collection occurred during breaks or after school during the basketball training sessions.

\section{Reliability of responses}

Reliability of player responses was verified by surveying their parents. Eight per cent of all parents $(N=458)$ were selected as about 30 repeated measures were needed to determine reliability. Thirty-six parents were randomly selected by applying a customised Visual Basics program to the young players' data. The parents of these players were telephoned after completion of data collection to verify the responses of the young players regarding whether an injury had been sustained during the season, and the location of the injury.

\section{Data analysis}

The questionnaire responses were entered into Microsoft Excel and then analysed descriptively using SAS Version 8. SAS programs were written to accommodate the multiple responses provided by the participants. Descriptive statistics were used. Percentages, means and standard deviations were calculated to describe the data set. Kappa statistic, which corrects for chance agreement, was used to determine the reliability of questionnaire responses. Probability calculations (odds ratios) were calculated and significant risk was identified by $95 \%$ confidence limits around odds ratios where neither $95 \%$ confidence limits encompass the value of 1 .

\section{Results}

\section{Sampling response}

Overall about $70 \%$ of the total population was captured; reasons for not capturing the additional $30 \%$ of the players are given in the methodology section. The response rate for the clubs was higher than for the schools (Table II).

\section{Sample characteristics}

The sample comprised 458 young basketball players in Cape Town, with 122 club players and 336 school basketball players. Table III summarises the age and gender of the sample.

\begin{tabular}{|lccc|}
\hline \multicolumn{2}{|c|}{ TABLE II. Response rate } & & \\
\hline & $\begin{array}{r}\text { Players' data } \\
\text { captured }(\boldsymbol{N})\end{array}$ & $\begin{array}{c}\text { Players' data not } \\
\text { captured }(\boldsymbol{N})\end{array}$ & $\begin{array}{c}\text { Response } \\
\text { rate (\%) }\end{array}$ \\
\hline Club players & 122 & 20 & 85.9 \\
School players & 336 & 180 & 651 \\
Total sample & 458 & 200 & 69.6 \\
\hline
\end{tabular}

\begin{tabular}{|ccccccc|}
\hline \multicolumn{7}{|c|}{ TABLE III. Sample description $(\%(N))$} \\
\hline Total & $\mathbf{1 4}$ yrs & & $\mathbf{1 5}$ yrs & 16 yrs & 17 yrs \\
\hline Boys & $68.0(312)$ & $22.7(104)$ & $16.4(75)$ & $15.7(72)$ & $13.3(60)$ \\
Girls & $32.0(146)$ & $9.6(44)$ & $13.8(63)$ & $5.6(26)$ & $2.8(13)$ \\
Mean age 15.2 years & & & & &
\end{tabular}

\section{Reliability of responses}

All 36 selected parents of injured and uninjured players participated in the study. The response was regarded as positive if they confirmed the child's reported injury and accurately described its location. If the parents could only confirm the injury and not location the response was regarded as negative. Good agreement was found between the player and parent responses (kappa statistic for agreement 0.89 (95\% Cl 0.74 - 1.03).

\section{Frequency of play}

The number of days and hours of basketball play were determined and are presented in Tables IV and V. Boys tended to play more often and for longer periods than girls.

\section{General injury rate}

The general injury rate was high, with $186(40.6 \%)$ of the total sample reporting that they sustained at least 1 injury over the season. Players could report an unlimited number of injured body parts. A total of 304 injured body parts were reported.

\begin{tabular}{|c|c|c|c|}
\hline \multicolumn{4}{|c|}{ TABLE IV. Frequency of play $(\%)$} \\
\hline $\begin{array}{l}\text { Days of play } \\
\text { per week }\end{array}$ & $\begin{array}{c}\text { Total Sample } \\
(N=458)\end{array}$ & $\begin{array}{c}\text { Males } \\
(N=312)\end{array}$ & $\begin{array}{l}\text { Females } \\
(N=14)\end{array}$ \\
\hline 1 Day & $9: 4$ & 5.4 & 178 \\
\hline 2 Days & 29.3 & 25.1 & 38.3 \\
\hline 3 Days & 24.9 & 28.3 & 17.8 \\
\hline 4 Days & 14.0 & 13.5 & 15.1 \\
\hline 5 Days & 9.2 & 10.6 & 61 \\
\hline 6 Days & 3.7 & 4.8 & 14 \\
\hline 7 Days & 9.4 & 12.2 & 34 \\
\hline Mean & & 36 & \\
\hline SD & & $1.7 \%$ & \\
\hline
\end{tabular}

\begin{tabular}{|lccc|}
\hline TABLE V. & Hours of play & & \\
\hline $\begin{array}{l}\text { Hours of play } \\
\text { per week }\end{array}$ & $\begin{array}{c}\text { Total sample } \\
(N=458)\end{array}$ & $\begin{array}{c}\text { Boys } \\
(N=312)\end{array}$ & $\begin{array}{c}\text { Girls } \\
(N=146)\end{array}$ \\
\hline Mean & 6.7 & 7.2 & 5.9 \\
SD & 4.0 & 4.2 & 3.6 \\
\hline
\end{tabular}




\begin{tabular}{|c|c|c|}
\hline \multicolumn{3}{|c|}{ TABLE VI, General injury rate } \\
\hline Injury location & $\begin{array}{l}\text { Number of } \\
\text { injured body parts }\end{array}$ & $\begin{array}{l}\text { Percentage of } \\
\text { all injuries } \\
(N=304)\end{array}$ \\
\hline Chest & 3 & 0.98 \\
\hline Neck & 3 & 0.98 \\
\hline Head & 4 & 131 \\
\hline Shoulder & 7 & 2.30 \\
\hline lower leg & 8 & 2.63 \\
\hline Thigh & 9 & 2.96 \\
\hline Eloow & 11 & 3.61 \\
\hline calf & 11 & 3.61 \\
\hline Arm & 14 & 460 \\
\hline Back & 15 & 4,93 \\
\hline Hand & 25 & 8.22 \\
\hline Wrist & 26 & 8.55 \\
\hline Ankle & 66 & 21.71 \\
\hline Knee & 97 & 31.90 \\
\hline
\end{tabular}

\section{Knee injury rate}

As noted in Table VI, the knee joint was the most commonly injured of all joints. The probability of sustaining a knee injury was also significantly more than sustaining an injury to another body part or no injury (OR $1.31,95 \% \mathrm{Cl} 1.15-1.50$ ). A total of 180 knee injuries was reported. Forty-eight individuals injured their knee once, 28 players injured their knees twice, 8 players injured their knees 3 times and 13 players injured their knees 4 or more times. Ninety-seven players sustained at least 1 knee injury indicating a rate of about 1 in 4.7 players.

The 180 knee injuries sustained also included recurrent injuries. Ninety of the injuries were recurrent. Of the 97 players who sustained knee injuries, 49 had a recurrent injury.

Players often sustained knee injuries in association with other injuries. The subgroup of players who only sustained an injury to the knee joint and no other injuries represented $10.5 \%(N=48)$ of the total sample $(N=458)$. A similar proportion of the players, $(10.7 \%, N=49)$ sustained an injury to the knee joint in association with another injury.

\section{Risk factors}

\section{Type of player}

School players were significantly less likely to sustain a knee injury compared with the club players (OR $0.62,95 \% \mathrm{Cl} 0.42$ $-0.93)$.

\section{Injury conditions}

In agreement with findings of previous research, most of the knee injuries $(48.6 \%, N=163)$ were sustained during competitions. $^{19}$ This trend was similar for boys and girls. Competition may be a significant risk factor for injury, with $48.6 \%$ of injuries occurring in competition and $19.4 \%$ in both competition and training, and may relate to overuse injuries or untreated or unhealed previous injuries. Thirty-two percent of injuries occurred in training only.

Injuries were recorded over the previous 7 months of the season. Most of the injuries $(21.5 \%, N=144)$ were sustained during the fourth month of the season and may be related to the intensive competition played during the period (Table VII).

\section{Gender}

No significant difference in knee injuries was found between boys and girls. Although knee-injured boys represented $71.1 \%(N=68)$ of the 97 individuals who sustained at least 1 knee injury, boys were no more likely to sustain a knee injury than girls (OR $1.19,95 \% \mathrm{Cl} 0.73-1.95)$. The knee injury rate in boys and girls was similar, as $22 \%(N=312)$ of all the boys and $19 \%(N=146)$ of girls in the sample reported an injury.

\section{Age}

The sample was divided into age groups and the risk of knee injury was compared with the 14-year-old group. No significant effect was found, therefore age does not appear to have a significant effect on knee injury (Table VIII).

The sample was split at the 15-year age group for descriptive purposes to gain insight into injuries sustained to the knee only, injuries sustained to the knee and an associated joint, and injuries to any other locations (Table IX).

Male and female players younger than 15 years old sustained more knee injuries than players aged 15 years and older. However the odds of younger players sustaining a knee injury compared with the older players were not significant (OR 1.04, 95\% Cl $0.72-1.49$ ).

\section{Participating in other sports}

Most of the young basketball players $(68.2 \%)$ in this study also participated in other sports. The other most common sports they played include soccer, hockey and rugby.

The group of basketball players who also participated in other sports sustained relatively fewer knee injuries $(19.6 \%$, $N=312$ ) compared with players not participating in other sports who presented with knee injuries $(24.8 \%, N=146)$. However the trend was evident only among the club players and not the school players. The odds ratio for all groups was not significant.

\section{Injury mechanisms}

A total of 144 mechanisms were reported for knee injuries, representing 13 different types of mechanisms. The most

TABLE VII. Knee injury related to the month (M) of play during the season $(\%)$

\begin{tabular}{|c|c|cccccc}
\hline & $M 1$ & $M 2$ & $M 3$ & $M 4$ & M & M 6 & $M 7$ \\
\hline$N=144$ & 146 & 97 & 187 & 215 & 152 & 90 & 111 \\
\hline
\end{tabular}

\begin{tabular}{|c|c|c|}
\hline TAB: & lated to injury & का \\
\hline Age group (yrs) & Odds ratio estimate & $95 \%$ Confidence limits \\
\hline $\begin{array}{l}14 \\
15 \\
16\end{array}$ & $\begin{array}{l}1 \\
0.96 \\
106 \\
0.67\end{array}$ & $\begin{array}{ll} & 0.55-1.69 \\
& 0.58-1.96 \\
& 0.32-1.39\end{array}$ \\
\hline
\end{tabular}


common injury mechanism among both boys and girls was landing badly from a jump. More than one-third of the knee injuries $(40.5 \%, N=144)$ were sustained as a result of landing badly. The second most common injury mechanism in general was 'falling' (13.2\%). However gender differences in injury mechanisms were observed, i.e. the second most common mechanism among boys was bumping into another player, whereas girls nominated falling (Table $X$ ).

The participants could also report on combined mechanisms and 'landing badly and falling' was the most common combination of injury mechanisms (Table X).

\section{Injury characteristics}

A total number of 146 symptoms reflecting 39 symptom combination complexes were reported. A symptom combination for 1 injury could be 'pain, swelling and locking'. The most common symptoms were pain (23.9\%), aching (17.8\%) and swelling $(5.5 \%)$. The most common symptom combination was 'swelling and pain' $(4.6 \%)$.

The location of the specific painful area at the knee joint was further explored. No gender differences were noted regarding the location of the painful area at the knee. Anterior knee pain was most frequently experienced by both boys and girls $(40.1 \%, N=127)$, followed by medial knee pain $(19.6 \%, N=127)$. Players could also report a combination of painful areas and pain experienced both medially and anterior to the knee joint $(14.1 \%, N=127)$ was the third most common area described.

\section{Injury severity}

Estimations of injury severity were based on the following criteria: (i) able to continue the game post injury; (ii) injury required first-aid before continuing the game, (iii) injury required medical consultation immediately after the injury; and (iv) injury resulted in loss of game or practice play.

\begin{tabular}{|c|c|c|c|c|}
\hline \multicolumn{5}{|c|}{$\begin{array}{l}\text { TABLE IX. Knee injury associated with injury to other } \\
\text { joints (\%) }\end{array}$} \\
\hline & $\begin{array}{c}\text { Boys } \\
<15 \text { yrs } \\
(N=104)\end{array}$ & $\begin{array}{c}\text { Girls } \\
<15 \text { yrs } \\
(N=44)\end{array}$ & $\begin{array}{c}\text { Boys } \\
\geq 15 \text { yrs } \\
(N=208)\end{array}$ & $\begin{array}{c}\text { Girls } \\
\geq 15 \text { yrs } \\
(N=102)\end{array}$ \\
\hline Only knee injury & 13.5 & 9.1 & 10.6 & 7.8 \\
\hline $\begin{array}{l}\text { Knee injury and } \\
\text { other injury }\end{array}$ & 9.6 & 11.5 & 11.1 & 10.8 \\
\hline Any other injury & 21.1 & 9.1 & 19.2 & 22.6 \\
\hline
\end{tabular}

\begin{tabular}{|c|c|c|c|}
\hline \multicolumn{4}{|c|}{ TABLE X Injury mechanisms (\%) } \\
\hline Mechanism & Girls & Boys & Overall \\
\hline Landing & 38.0 & 43.0 & 40.5 \\
\hline $\begin{array}{l}\text { Bumping into } \\
\text { another player }\end{array}$ & 12.0 & 15.0 & 13.5 \\
\hline Falling & 19.0 & 13.0 & 16.0 \\
\hline $\begin{array}{l}\text { Landing and overuse } \\
\text { pain }\end{array}$ & 0 & 8.0 & 4.0 \\
\hline Overuse & 12.0 & 13.0 & 12.5 \\
\hline Trpping & 170 & 10.0 & 13.5 \\
\hline
\end{tabular}

Knee injuries resulting in loss of practice or game play were regarded as the most serious injuries. Sixty injuries resulted in loss of game or practice play, indicating a knee injury prevalence for serious injuries of about $33.3 \%$ $(N=180)$. Thirty-two injuries resulted in loss of play for less than a week, 20 injuries resulted in loss of play for more than a week and only 6 injuries caused players to stop playing for more than a month. Information regarding the other 2 injuries were incomplete. It is proposed that injuries resulting in loss of 5 or more player opportunities, i.e. practice or competition, should be regarded as more serious injuries. ${ }^{14}$ This would indicate that about 26 of the knee injuries $(14.4 \%, N=180)$ were serious in this sample.

Although younger players sustained more injuries than older players, older players sustained more serious injuries. There were $14.8 \%(N=47)$ serious injuries among the 14year-old players, $23.9 \%(N=45)$ among the 15 year-old players, $28.1 \%(N=32)$ among the 16 -year-old players and $64 \%$ $(N=17)$ among the 17 -year-old players.

Injuries sustained by landing badly from a jump were also more serious compared with other mechanisms. About $29.6 \%(N=54)$ of injuries that involved landing as an injury mechanism were regarded as more serious. All other mechanisms only resulted in about 90 serious injuries (24\%).

\section{Injury management}

Most injuries were not treated at all $(63.4 \%, N=143)$. No difference was found between the proportion of treated injuries in clubs (36\%) and schools (36.6\%). More severe injuries were treated more often than minor injuries. About $25 \%$ $(N=60)$ of the injuries that resulted in loss of play were treated and only $20 \%(N=84)$ of injuries that cid not result in a loss of play were treated.

The initial injuries were less well managed. This is evidenced by $35 \%(N=143)$ of the initial injuries being treated; $36 \%$ of the second injuries sustained were managed and $50 \%$ of the third injuries were treated.

Most injuries were conservatively managed with medication only $(25 \%)$. A small number of injuries were managed with physiotherapy $(7.6 \%)$. Poor injury management may be one reason for the high recurrence rate of knee injuries. Notably conservative management such as 'medication and rest' $(5.6 \%, N=143)$ was the most common form of treatment and was the most frequently reported combination of treatment methods.

\section{Discussion}

Basketball has been reported to have the highest rate of injury among non-contact sports. ${ }^{9.12}$ Considering the growth rate of basketball in South Africa, it is imperative that investigations into the epidemiology of basketball injuries are conducted to identify causal factors that could aid in prevention and appropriate management of injuries.

This is the first known research into injury among young South African basketballers. The general injury rate of this sample $(40.6 \%)$ and the most common injury locations (the knee and ankle) agree with findings of previous reports. ${ }^{15}$ However the knee injury patterns differed from those in pre- 
vious research. ${ }^{12}$ The percentage of knee injury (39\%) is higher than findings from other studies (approximately 10 $20 \%)^{1.6,20}$ The injury definition chosen for this study may explain the higher injury rate. This definition identified injuries resulting from both direct and indirect mechanisms such as overuse injuries. As noted previously, the other studies restricted injury definition to injuries that resulted in loss of play. All injuries were included in this study and the requirement that the injury must result in loss of play to be recorded as an injury was not employed. ${ }^{2}$ Overuse injuries are estimated to comprise about $13 \%$ of all the mechanisms found in this study. Exclusion of these injuries may lead to an underestimate of the basketball injury rate, particularly the most common knee diagnoses among young basketball players, viz. overuse conditions such as patellar tendonitis. ${ }^{8}$ Such conditions may be as detrimental to players as traumatic injuries and may later result in loss of play as the condition progresses and the degenerative process become more apparent. It is of note that if injuries are defined as in prior studies, i.e. the injury must result in loss of play, the knee injury rate of this study would be $13.1 \%(N=458)$ and thus comparable to previous reports.

The overuse injury mechanism may also be related to the reported symptoms. Pain was the most common symptom experienced and the location of the pain was mainly anterior to the knee joint $(40.1 \%, N=127)$. A shortcoming of many studies is that specific diagnoses cannot be determined since the injuries are self-reported. However anterior knee pain is usually related to overuse conditions such as patellar tendinitis, patellofemoral joint pain, fat pad disorders, etc. These knee injury characteristics are in agreement with clinic-based studies reporting that the most common diagnosis made at sports medicine clinics is patellofemoral pain. ${ }^{2,18}$

Club players were significantly more at risk of sustaining a knee injury than school players. Club-level play is more aggressive and is at a higher level than the school league. More incentives are offered to club players and this may serve as a motivational factor to train and piay more often and for longer periods.

The knee injury rate has been reported to be higher among girls than boys. ${ }^{1.12}$ Serious knee injuries such as anterior cruciate ligament lesions were responsible for the higher injury rate among girls. The results of this study differ from previous reports as the knee injury prevalence among boys $(22 \%, N=312)$ and girls $(19 \%, N=146)$ was similar. The level of play among young South African girls may be less aggressive than the level of play in countries where basketball has been played for longer, such as the United States of America. Since the injuries were self-reported, specific diagnoses were not recorded and therefore the number of anterior cruciate ligament injuries cannot be determined from these data.

Another explanation for the comparable knee injury rate between boys and girls may be related to exposure of play. In this sample the boys played more frequently than the girls (Table VIII). Therefore boys are more exposed to injury compared with the girls in this sample. The knee injury rate among the girls in this sample may therefore be higher than that of boys if exposure was standardised between boys and girls. However difficulty in accurately determining exposure time particularly in team sports like basketball where players are rotated during game play has been recognised and was not determined in this study. ${ }^{1}$ Exposure for this study was also not determined since the aim of the study was mainly to identify injury patterns and not necessarily to compare the risk across sports.

In agreement with previous research, landing badly was the most common injury mechanism and resulted in more serious injuries as measured by time lost from play or medical attention..$^{7,911,17}$ Landing is a complex task and requires good co-ordination, dynamic muscle control, flexibility, etc. Landing in either a varus or valgus lower extremity alignment creates a less stable position for the knee, leading to off-balance landings.? This produces high landing forces and moments which coupled with the dynamic nature of basketball may render young basketball players vulnerable to injury of the lower extremity.

Falling and tripping were more common among girls whereas 'bumping into another player' was reported as the second most common mechanism among boys. This finding may be an indication of the differences in level of play between boys and girls. Girls may play with greater care, but may be relatively more prone to falling or tripping due to comparatively lower levels of skill or control. More research needs to be done in this area.

Most of the injuries reported were not treated. The growth rate of basketball in South Africa since 1992 is mostly attributed to the increase in number of players from relatively poorer socio-economic backgrounds. More than $80 \%$ of the registered competitive players in the Western Cape are from previously disadvantaged communities. Parents may not be able to afford or identify appropriate management and Basketball South Africa does not have medical support structures for injured players. Inappropriate or no management may be one reason for the high recurrence rate of the injuries. Thirteen players $(N=458)$ indicated that they sustained a knee injury more than 4 times and in most cases the initial injury was not treated. This could predispose players to subsequent injuries. A very small number of players consulted a physiotherapist. Most players who had treatment used medication (25\%). Education of all participants such as the coaches, parents, players, teachers, etc. is needed to encourage dynamic rehabilitation of injuries as opposed to only more traditional medical management approaches.

The small number of players who consulted a physiotherapist may also be a refiection of inadequate promotional programmes conducted by physiotherapists. Physiotherapists adopt a proactive approach to focus on preventative aspects as well as rehabilitative programmes. The discrepancy between the number of players who received physiotherapy and medical treatment may indicate that interdisciplinary health management should be re-emphasised. Medical practitioners are not always aware of the type of conditions treated by physiotherapists since it does not form part of their formal training. ${ }^{10}$ Consequently appropriate clients are not referred for further management and players may be at risk of injury recurrence due to inadequate preparation to ensure safe return to sport. 


\section{Conclusion}

The knee injury rate among young basketball players in Cape Town is high. Better awareness of the epidemiology might improve coaches', parents' and health professionals' understanding and management of knee injuries among young basketball players. An awareness of the scope of the problern may also improve the education of players regarding injury prevention and recurrence based on knowledge of the injury mechanisms and possible risk factors.

Comprehensive strategies to prevent injuries are also urgently required. Unfortunately there is a shortage of research indicating successful programmes to prevent injuries. Further research into the causative mechanisms, risk factors, etc. is therefore required before sound preventative measured can be implemented. This study is the first to document the knee injury rate and associated factors among young South African basketball players. It also provides insight into the prevalence of overuse injuries compared with previous international studies. Future prospective studies that address possible recall bias and attempts to monitor exposure time will provide additional insight into the epidemiology of the knee injuries in basketball.

\section{Acknowledgements}

Financial support for the study was granted by the Medical Research Council.

Quinette Louw was granted the 'President's Award' scholarship by the University of South Australia.

The authors would like to express sincere appreciation to Denric Blaauw, Wilfred Allen and Laura Radcioff for their invaluable assistance in collecting the data.

\section{REFERENCES}

1. Arendt $E$, Dick R. Knee injury patterns among men and women collegiate basketball and soccer. Am J Sports Med 1995; 23: 694-701.

2. Bacqui $P$, Brukner P. Injuries presenting to an Australian Sports Medicine Centre. Clin J Sports Med 1996; 7: 28-31.

3. De Loes M. Medical treatment and cost of sports-related injuries in a total population. International Journal of Sports Injuries 1990; 11: 66-72.

4. Emerson R. Basketball knee injuries and the anterior cruciate ligament. Clin Sports Med 1993; 12: 317-28.

5. Feinstein A. Director, Premier Basketball League, South Africa. www.basketball.co.za (Accessed March 1998)

6. Gomez $E$, De Lee J, Farney $W$. Incidence of injury in Texas high school basketball. Am J Sports Med 1996; 24: 684 - 7.

7. Hewett T, Stroupe A, Nance T, Noyes F. Plyometric training in female athletes. Am J Sports Med 1996, 24: 765-73.

8. Hicky G, Fricker P, McDonald W. Injuries to young elite basketball players over a six year period. Clin J Sport Med 1997, 7: 252 - 6 .

9. Jones D, Louw Q, Grimmer K. Recreational and sporting injury to the adolescent knee and ankle: Prevalence and causes. Australian Journal of Physiotherapy 2000; 46: 179-88.

10. Lee K, Sheppard L. An investigation into medical students; knowledge and perception of physiotherapy services. Australian Journal of Physiotherapy 1998; 44: 239-45.

11. McKay G, Goldie P, Payne W, Oakes B, Watson L. A prospective study of injuries in basketball: $A$ total profile and comparison by gender and standard of competition. J Sci Med Sport 2001; 4: 196-211.

12. Messina D, Farney $W$, De Lee J. The incidence of injury in Texas high school basketball. Am J Sport Med 1999; 27: 294-9.

13. Micheli L, Metzl J, Di Canzio D. Anterior reconstructive surgery in adolescent soccer and basketball players. Clin J Sport Med 1999; 9: 138-41.
14. Phillips L. Sports injury incidence. Br J Sports Med 2000; 34: 133-6.

15. Powell J, Barber - Foss K. Sex related injury patterns among selected high school sports. Am J Sports Med 2000; 28: 385-91.

16. Pritchett J. A claims-made study of knee injuries due to football in high school athletes. J Pediatric Orthop 1988; 8: 551-3.

17. Steele J. Minimising lower limb injuries in sports. Presented at the Fifth IOC World Congress in Sport Sciences, Sydney, Australia, 31 Dctober 5 November 1999.

18. Witman $P$, Melvin $M$, Nicholas $J$, et al. Common problems seen in a metropolitan sports injury clinic. Physician and Sports Medicine 1981; 9: 1058.

19. Yde J, Nielsen M. Sports injuries in adolescents' ball games: soccer, handball and basketball. Br J Sports Med 1990; 24: 51-4.

20. Zelisko J, Noble HB, Porter M. A comparison of men's and women's professional baskethall injuries. Am J Sports Med 1982; 10: 297-9. 